\title{
BMJ Open E-cigarette use in Canada: prevalence and patterns of use in a regulated market
}

\author{
Samantha Shiplo, Christine D Czoli, David Hammond
}

To cite: Shiplo S, Czoli CD, Hammond D. E-cigarette use in Canada: prevalence and patterns of use in a regulated market. BMJ Open 2015;5: e007971. doi:10.1136/ bmjopen-2015-007971

- Prepublication history for this paper is available online. To view these files please visit the journal online (http://dx.doi.org/10.1136/ bmjopen-2015-007971).

Received 13 February 2015 Revised 5 May 2015 Accepted 7 May 2015

School of Public Health \& Health Systems, University of Waterloo, Waterloo, Ontario, Canada

Correspondence to Dr David Hammond; dhammond@uwaterloo.ca

\section{ABSTRACT}

Objective: Canada is among the few countries in which e-cigarettes containing nicotine are prohibited. To date, there is little evidence on the prevalence and patterns of use of e-cigarettes in markets with product bans. The current study examines e-cigarette use among a sample of non-smokers and smokers in Canada.

Design: Online cross-sectional survey.

Setting: Conducted in October 2013 using a commercial panel of Canadians from Global Market Insite, Inc (GMI).

Participants: In total, 1095 Canadians were included in the analysis: 311 non-smokers aged 16-24 years (younger non-smokers), 323 smokers aged 1624 years (younger smokers) and 461 smokers 25 years and older (older smokers).

Primary and secondary outcome measures: E-cigarette ever and current use, types of products used, and reasons for use.

Results: Approximately $79 \%$ of younger non-smokers, $82 \%$ of younger smokers and $81 \%$ of older smokers were aware of e-cigarettes. Ever trial of e-cigarettes was reported by $10 \%$ of younger non-smokers, $42 \%$ of younger smokers and $27 \%$ of older smokers. Moreover, current use of an e-cigarette, which was defined as use in the last 30 days, was reported by $0.3 \%$ of younger non-smokers, $18 \%$ of younger smokers and $10 \%$ of older smokers. Among those who had ever tried an e-cigarette, approximately $10 \%$ of younger non-smokers, $46 \%$ of younger smokers and $43 \%$ of older smokers reported trying an e-cigarette that contained nicotine. The most popular e-cigarette flavours were fruit followed by menthol, and the most common reason for using ecigarettes was to help them quit smoking.

Conclusions: In the context of previous research, it appears that the prevalence of e-cigarette trial has increased in Canada. Although a considerable proportion of non-smokers have tried e-cigarettes, current use is almost entirely concentrated among smokers. Further research should be conducted to monitor e-cigarette use by Canadians.

\section{INTRODUCTION}

Tobacco use is the leading cause of preventable death in Canada. ${ }^{1}$ Cigarettes contain

\section{Strengths and limitations of this study}

- The study describes prevalence and patterns of e-cigarette use among both non-smokers and smokers in a regulated market.

- The data are drawn from a convenience sample and thus, are not representative of the Canadian population.

- The study is cross-sectional preventing causal inferences between e-cigarette use and smoking behaviour.

more than 4000 chemicals, including more than 60 carcinogens. ${ }^{2}$ Electronic cigarettes, also known as e-cigarettes or electronic nicotine delivery systems, contain batteries that heat and emit vapour from a liquid solution that typically contains glycerine, propylene glycol, flavours and nicotine. ${ }^{3}$ Unlike 'conventional' cigarettes, e-cigarettes do not contain tobacco and no combustion takes place. A systematic review of chemical, toxicological and clinical studies on the potential risks from e-cigarette use concluded that some toxic chemicals are released in the e-cigarette vapour, but their levels are substantially lower than in tobacco smoke and in some cases, are comparable to those found in nicotine replacement therapy (NRT). ${ }^{4}$ Although the long-term health risks of e-cigarette use are not yet known, vapourised nicotine products are likely to pose some level of health risk, but a markedly lower level of risk than combusted tobacco products. ${ }^{35}$

The prevalence of e-cigarette use has rapidly increased. Globally, the e-cigarette market is valued at $\$ 2$ billion a year and it is expected to exceed $\$ 10$ billion a year by $2017 .{ }^{6} 7$ In the US, the most recent estimate indicates that $32.2 \%$ of current smokers have tried an e-cigarette. ${ }^{8}$ Although there is limited data for Canada, a study of current and former adult smokers indicated that $10 \%$ had tried e-cigarettes between 2010 and 2011. ${ }^{9}$ The use of e-cigarettes remains 
substantially higher among current and former smokers, compared to non-smokers; ${ }^{10} 11$ nevertheless, an increasing proportion of non-smokers also report trying e-cigarettes: $1 \%$ and $5.2 \%$ of non-smokers reported trying e-cigarettes in the US and Canada, respectively. ${ }^{8} 12$ Despite increasing rates of 'trying' e-cigarettes, rates of current e-cigarette use among non-smokers are substantially lower. ${ }^{8}$ For instance, current use of e-cigarettes among non-smokers was reported as $0.04 \%$ among adults in the US, and approximately $1 \%$ among young adults in Canada. ${ }^{12}$ A similar pattern is apparent among smokers with respect to patterns of regular use: only a minority of smokers who report trying e-cigarettes report regular use, in terms of weekly or daily use of e-cigarettes. ${ }^{9}$

The e-cigarette market is characterised by a wide variety of product designs and constituents. ${ }^{13}$ A number of these product features are cited as an important motivation for use, such as product flavours. ${ }^{11} 1415$ However, the extent to which product characteristics, such as flavour, differentially target distinct subgroups is largely unknown. Whereas advocates of e-cigarettes have argued that flavours have the potential to promote greater substitution for combustible products among smokers, opponents of e-cigarettes have argued that the range of flavours on the market primarily target young non-smokers. Currently, we are unaware of any studies that have compared the prevalence of flavoured product use among smokers and non-smokers.

To date, there is relatively little data on how e-cigarettes are being used by smokers in ways that may reduce, sustain, or even promote smoking behaviour. According to an European study, $76 \%$ of e-cigarette users started using e-cigarettes as an alternative to smoking cigarettes and $7 \%$ to quit smoking altogether. ${ }^{15}$ In the UK, e-cigarettes are now the most popular smoking cessation aid. ${ }^{16}$ Other reasons people use e-cigarettes are to cut down the number of cigarettes smoked, to reduce the costs of smoking, to stop disturbing others with smoke, and to circumvent smoking restrictions. ${ }^{14}{ }^{15} \mathrm{~A}$ recent study of e-cigarette users in the US found that the most common reason for use was 'just because' followed by 'to quit smoking', 'safer than smoking' and 'easy to use when I can't smoke'. ${ }^{8}$ Additional evidence regarding e-cigarette use for the purpose of quitting versus other reasons is critically important for interpreting population-based estimates of smoking abstinence associated with e-cigarette use.

The regulatory framework for e-cigarettes varies widely by country. In Canada, electronic smoking products containing nicotine are regulated under the Food and Drugs Act. Market authorisation is required for all of these products prior to being imported, advertised or sold in Canada; to date, no e-cigarette product has received such market approval. Therefore, the marketing and sale of e-cigarettes containing nicotine, including e-liquid, is illegal. ${ }^{17}$ In contrast, e-cigarettes that do not contain nicotine and do not make health claims are sold legally in mainstream retail outlets. Overall, e-cigarettes with and without nicotine are widely available in Canada, although the proportion of 'legal' and 'illegal' e-cigarettes is largely unknown. Given the limited evidence surrounding electronic smoking products, Health Canada has issued public advisories against using these products, as these 'may pose health risks and have not been fully evaluated for safety, quality, and efficacy'. ${ }^{18}$

The current study sought to examine e-cigarette use among a sample of non-smokers and smokers in Canada. In particular, the study sought to assess: (1) prevalence and frequency of e-cigarette use; (2) e-cigarette product characteristics, including nicotine content and flavours; (3) reasons for using e-cigarettes and (4) sociodemographic correlates of e-cigarette use.

\section{METHODS}

\section{Study design and protocol}

An online cross-sectional survey was conducted in Canada in October 2013. Sociodemographic information was collected followed by various questions regarding e-cigarette awareness, use and product types. Prior to the study, a sample size calculation was conducted to determine adequate power for a balanced incomplete block design discrete-choice experiment with a $4 \times 4 \times 4 \times 2$ design. All of the measures reported in the current paper were administered prior to the discrete choice experiment.

\section{Participants}

Canadian participants aged 16 years and older were recruited using a commercial panel from Global Market Insite, Inc (GMI). GMI panel members were sent an email invitation with a link directly to the survey and were reimbursed approximately $\$ 2$ for completing the survey. Sample targets were established to recruit a minimum of 350 participants for each of three priority subgroups with respect to e-cigarette use: younger nonsmokers aged 16-24 years, smokers aged 16-24 years and smokers aged 25 years and older. These groups were selected to examine whether e-cigarette use differed by age and smoking status. Additional information regarding GMI is available online (http://www.gmi-mr.com/ global-panel/panel-quality.php). A total of 1095 respondents were included in the analyses, after excluding participants with missing information for ethnicity $(n=15)$, education $(\mathrm{n}=6)$, smoking status $(\mathrm{n}=18)$, e-cigarette awareness $(n=3)$, ever use of e-cigarettes $(n=2)$, as well as participants who were identified as former smokers $(n=49)$.

\section{Measures}

\section{Sample characteristics}

Demographic variables included gender, age, ethnicity and education. Ethnicity was classified as white or nonwhite (including South Asian, Chinese, Black, Filipino, 
Latin American, Arab, Southeast Asian, West Asian, Korean, Japanese, Aboriginal or multiracial). Education was defined as the highest level of formal education completed at the time of the study. Education levels included: low (high school or less), moderate (technical/ trade school, community college, or some university, but no degree), and high (university degree or more).

Smokers were defined as those who had smoked 100 cigarettes in their lifetime and had smoked in the last 30 days. Non-smokers were those who had not smoked in the last 30 days and who had smoked $<100$ cigarettes in their lifetime. Smoking status and age were combined using the quotas to create three categories: younger nonsmokers aged 16-24 years old, younger smokers aged 1624 years old and older smokers aged 25 years and older. Intention to quit smoking was analysed by asking whether smokers were planning to quit within 6 months, beyond 6 months, or not planning to quit.

\section{Prevalence of e-cigarette use}

E-cigarette awareness was ascertained by asking participants whether they had ever heard of electronic cigarettes or e-cigarettes before the study. E-cigarette use was determined by asking participants whether they had ever tried an electronic or smokeless cigarette, also known as 'e-cigarettes' and whether they had used an e-cigarette in the last 30 days. Current use was defined as having tried an e-cigarette and having used one in the last 30 days. Participants identified as current e-cigarette users were asked whether they used e-cigarettes monthly, weekly or daily.

\section{Patterns of e-cigarette use}

Temporality of using cigarettes and e-cigarettes was determined by asking: 'In your lifetime, which product did you try first, a regular tobacco cigarette or an e-cigarette'?

\section{E-cigarette products}

Ever flavour use and last flavour use of e-cigarettes was determined by asking participants if they had ever tried or last used 'an e-cigarette that was flavoured to taste like menthol, mint, or any other flavour such as spice, candy, fruit, or alcohol'? and participants could select as many flavours, as applied. Ever and last use of e-cigarettes containing nicotine were reported along with ever and current e-cigarette brands used.

\section{Reasons for e-cigarette use}

Participants who had ever tried e-cigarettes were asked why they first tried an e-cigarette by using a precoded checklist including the following responses: 'someone offered me one'; 'I thought it would be fun'; 'I thought it might taste good'; 'I was curious what it would be like'; 'I thought it could help me quit smoking'; 'I thought it might be less harmful to me than a cigarette' and 'I wanted to use it in a place where I couldn't smoke'. Current e-cigarette users were asked: 'Please tell us why you currently use e-cigarettes'. Responses were: 'they are affordable'; 'they are fun to use'; 'they taste good'; 'using an e-cigarette might help me to quit smoking'; 'they might be less harmful to me than cigarettes'; 'they might be less harmful to people around me than cigarettes' and 'I can use e-cigarettes in places where smoking isn't allowed'. Furthermore, smokers were asked which products they would use to quit smoking with responses: nicotine gum, patch, lozenges, e-cigarettes, and prescription medication.

\section{Analysis}

Differences between sample categories were tested using $\chi^{2}$ tests for sex, ethnicity, education level, smoking status and intention to quit smoking. Logistic regression models examined factors associated with e-cigarette awareness $(0=$ not aware, $1=$ aware $)$, ever use $(0=$ no ever use, $1=$ ever use), current use $(0=$ no current use, $1=$ current use), use of flavours $(0=$ never used a flavoured e-cigarette, 1=used a flavoured e-cigarette) and nicotine $(0=$ never used an e-cigarette with nicotine, $1=$ =used an e-cigarette with nicotine). All models included the covariates sex, ethnicity and education level and categories, and adjusted ORs were reported in all cases. Analyses were conducted using SPSS, V.22 (IBM).

\section{RESULTS}

\section{Sample characteristics}

Table 1 shows sample characteristics. Significant differences were found across categories for sex $\left(\chi^{2}=24.5\right.$, $\mathrm{p}<0.001)$, ethnicity $\left(\chi^{2}=27.4, \mathrm{p}<0.001\right)$, and education $\left(\chi^{2}=14.4, \mathrm{p}=0.01\right)$. There were also significant differences in the smoking frequencies between younger smokers and older smokers $\left(\chi^{2}=2423.1, \mathrm{p}<0.001\right)$, as the highest proportion of daily smokers were older smokers. No significant differences between younger smokers' and older smokers' intentions to quit smoking were found $\left(\chi^{2}=2.4, \mathrm{p}=0.66\right)$.

\section{Prevalence of e-cigarette use}

Awareness of e-cigarettes was reported by $79.1 \%$ of younger non-smokers ( $\mathrm{N}=246), 82.4 \%$ of younger smokers $(\mathrm{N}=266)$ and $81.1 \%$ of older smokers $(\mathrm{N}=374)$. Logistic regression analysis examined factors associated with e-cigarette awareness and found that non-white respondents were less likely to be aware of e-cigarettes than white respondents ( $\mathrm{OR}=0.49,95 \%$ CI 0.35 to 0.68 ; $\mathrm{p}<0.001)$. Levels of awareness did not differ by sex, age, education or smoking status.

Table 2 shows the prevalence of e-cigarette ever use and current use. A logistic regression examined ever use of e-cigarettes adjusting for sex, ethnicity and education, which showed that ever use of e-cigarettes varied by smoking status $\left(\chi^{2}=72.28, \mathrm{p}<0.001\right)$. Younger non-smokers were less likely to try e-cigarettes than younger smokers $(\mathrm{OR}=0.16,95 \%$ CI 0.10 to $0.24 ; \mathrm{p}<0.001)$ and older smokers $(\mathrm{OR}=0.32,95 \%$ CI 0.21 to $0.50 ; \mathrm{p}<0.001)$. Ever use of e-cigarettes was less common among older smokers 
Table 1 Sample table $(\mathrm{N}=1144)$

\begin{tabular}{|c|c|c|c|}
\hline Characteristic & $\begin{array}{l}\text { Younger non-smokers } \\
16-24 \text { years } \\
(\mathrm{N}=311)\end{array}$ & $\begin{array}{l}\text { Younger smokers } \\
16-24 \text { years } \\
(\mathrm{N}=323)\end{array}$ & $\begin{array}{l}\text { Older smokers } \\
25+\text { years } \\
(\mathrm{N}=461)\end{array}$ \\
\hline Mean age & 20.51 & 21.35 & 48.52 \\
\hline \multicolumn{4}{|l|}{ Sex } \\
\hline Male & $34.4 \%(107)$ & $38.1 \%(123)$ & $51.0 \%(235)$ \\
\hline Female & $65.6 \%(204)$ & $61.9 \%(200)$ & $49.0 \%(226)$ \\
\hline \multicolumn{4}{|l|}{ Ethnicity } \\
\hline White & $68.5 \%(213)$ & $75.9 \%(245)$ & $84.4 \%$ (389) \\
\hline Non-white & $31.5 \%(98)$ & $24.1 \%(78)$ & $15.6 \%(72)$ \\
\hline \multicolumn{4}{|l|}{ Education } \\
\hline Low & $39.9 \%(124)$ & $38.7 \%(125)$ & $30.4 \%(140)$ \\
\hline Moderate & $35.0 \%(109)$ & $42.1 \%(136)$ & $41.9 \%(193)$ \\
\hline High & $25.1 \%(78)$ & $19.2 \%(62)$ & $27.8 \%(128)$ \\
\hline \multicolumn{4}{|l|}{ Smoking status } \\
\hline Daily & - & $53.6 \%(173)$ & $84.8 \%(391)$ \\
\hline Weekly & - & $25.7 \%(83)$ & $9.3 \%(43)$ \\
\hline Monthly & - & $20.7 \%(67)$ & $5.9 \%(27)$ \\
\hline \multicolumn{4}{|l|}{ Intention to quit } \\
\hline Within 6 months & - & $43.0 \%(139)$ & $43.2 \%(199)$ \\
\hline Beyond 6 months & - & $33.1 \%(107)$ & $29.1 \%(134)$ \\
\hline Not planning to quit & - & $15.8 \%(51)$ & $17.8 \%(82)$ \\
\hline Do not know & - & $7.7 \%(25)$ & $9.8 \%(45)$ \\
\hline
\end{tabular}

compared to younger smokers $(\mathrm{OR}=0.49,95 \%$ CI 0.36 to $0.67 ; \mathrm{p}<0.001)$. In addition, non-white respondents $\left(\chi^{2}=6.64, \mathrm{OR}=0.61,95 \%\right.$ CI 0.42 to $\left.0.89 ; \mathrm{p}=0.01\right)$ and those with high education $\left(\chi^{2}=4.33\right.$, OR $=0.66,95 \%$ CI 0.45 to $0.98 ; \mathrm{p}=0.04$ ) were less likely to ever try e-cigarettes, however, ever use did not differ by sex $\left(\chi^{2}=0.18, \mathrm{OR}=0.94,95 \%\right.$ CI 0.70 to $\left.1.26 ; \mathrm{p}=0.67\right)$.

Current use of e-cigarettes was analysed using a logistic regression model adjusting for sex, ethnicity and education, which found that current use differed by smoking status $\left(\chi^{2}=25.74, \mathrm{p}<0.001\right)$. Younger non-smokers were less likely to be current e-cigarette users than younger smokers $(\mathrm{OR}=0.02,95 \%$ CI 0.00 to $0.11 ; \mathrm{p}<0.001)$ and older smokers $(\mathrm{OR}=0.03,95 \%$ CI 0.00 to $0.22 ; \mathrm{p}=0.001)$. Current e-cigarette use was less common among older smokers compared with younger smokers $(\mathrm{OR}=0.49,95 \% \mathrm{CI}$ 0.32 to $0.75 ; \mathrm{p}=0.001)$. Current use of e-cigarettes did not differ by sex $\left(\chi^{2}=3.32\right.$, OR $=0.67,95 \%$ CI 0.44 to 1.03 ; $\mathrm{p}=0.07)$, ethnicity $\left(\chi^{2}=0.16, \mathrm{OR}=0.89,95 \%\right.$ CI 0.44 to 1.03; $\mathrm{p}=0.69)$, or education $(\chi 2=5.31, \mathrm{p}=0.07)$.

\section{Patterns of e-cigarette use}

Dual use of tobacco cigarettes and e-cigarettes was reported by $13.3 \%$ of smokers. Among all of the respondents who had ever tried both tobacco cigarettes and e-cigarettes $(\mathrm{N}=289), 7.5 \%(\mathrm{~N}=12)$ of younger non-smokers, $90.4 \%(\mathrm{~N}=123)$ of younger smokers, and $91.9 \%(\mathrm{~N}=113)$ of older smokers tried cigarettes first. Additionally, $18.8 \%$ $(\mathrm{N}=3)$ of younger non-smokers, $9.6 \% \quad(\mathrm{~N}=13)$ of younger smokers, and $6.5 \%(\mathrm{~N}=8)$ of older smokers tried e-cigarettes first and $6.3 \%(\mathrm{~N}=1)$ of younger non-smokers, zero younger smokers, and $1.6 \%(\mathrm{~N}=2)$ of older smokers did not know which product they tried first.

Table 2 Prevalence of e-cigarette use $(\mathrm{N}=1144)$

\begin{tabular}{|c|c|c|c|}
\hline Characteristic & $\begin{array}{l}\text { Younger non-smokers } \\
16-24 \text { years } \\
(\mathrm{N}=311) \\
\%(\mathrm{n})\end{array}$ & $\begin{array}{l}\text { Younger smokers } \\
16-24 \text { years } \\
(\mathrm{N}=323) \\
\%(n)\end{array}$ & $\begin{array}{l}\text { Older smokers } \\
25+\text { years } \\
(\mathrm{N}=461) \\
\%(\mathrm{n})\end{array}$ \\
\hline $\begin{array}{l}\text { E-cigarette ever use } \\
\text { E-cigarette current use }\end{array}$ & $10.0(31)$ & $42.1(136)$ & 26.7 (123) \\
\hline None & 99.7 (310) & $82.0(265)$ & $90.0(415)$ \\
\hline Any & $0.3(1)$ & $18.0(58)$ & $10.0(46)$ \\
\hline Daily & 0.0 & $2.8(9)$ & $1.7(8)$ \\
\hline Weekly & $0.3(1)$ & $3.4(11)$ & 3.7 (17) \\
\hline Monthly & 0.0 & $11.8(38)$ & $4.6(21)$ \\
\hline
\end{tabular}


Table 3 Flavoured e-cigarette ever use $(\mathrm{N}=304)$

\begin{tabular}{|c|c|c|c|}
\hline Characteristic & $\begin{array}{l}\text { Younger non-smokers } \\
16-24 \text { years } \\
(\mathrm{N}=31) \\
\%(\mathrm{n})\end{array}$ & $\begin{array}{l}\text { Younger smokers } \\
16-24 \text { years } \\
(\mathrm{N}=136) \\
\%(\mathrm{n})\end{array}$ & $\begin{array}{l}\text { Older smokers } \\
25+\text { years } \\
(\mathrm{N}=123) \\
\%(\mathrm{n})\end{array}$ \\
\hline No flavour & $22.6(7)$ & $14.7(20)$ & 35.0 (43) \\
\hline Any & $77.4(24)$ & $84.6(115)$ & $64.2(79)$ \\
\hline Fruit & 45.8 (11) & $56.6(77)$ & $28.5(35)$ \\
\hline Menthol & $16.7(4)$ & 33.8 (46) & 30.9 (38) \\
\hline Tobacco & 0.0 & 26.5 (36) & 24.4 (30) \\
\hline Candy & $8.3(2)$ & $19.1(26)$ & $12.1(15)$ \\
\hline Coffee & $4.2(1)$ & $16.9(23)$ & $13.0(16)$ \\
\hline Spice & $8.3(2)$ & $4.4(6)$ & $5.7(7)$ \\
\hline Alcohol & 0.0 & $7.4(10)$ & $3.3(4)$ \\
\hline Other & $8.3(2)$ & $2.9(4)$ & $1.6(2)$ \\
\hline Do not know & $16.7(4)$ & 0.0 & 0.0 \\
\hline
\end{tabular}

Table 3 shows flavours used by e-cigarette ever users. A logistic regression model examining factors associated with e-cigarette flavour use adjusted for sex, ethnicity and education showed that the use of flavoured e-cigarettes varied by smoking status $\left(\chi^{2}=74.66, \mathrm{p}<0.001\right)$. Younger non-smokers were less likely to try a flavoured e-cigarette than younger smokers ( $\mathrm{OR}=0.13,95 \%$ CI 0.08 to $0.22 ; \mathrm{p}<0.001)$ and older smokers $(\mathrm{OR}=0.36,95 \% \mathrm{CI}$ 0.22 to $0.62 ; \mathrm{p}<0.001)$. Furthermore, it was less common for older smokers to use flavoured e-cigarettes compared to younger smokers $(\mathrm{OR}=0.36,95 \%$ CI 0.25 to 0.51 ; $\mathrm{p}<0.001)$.

Among those who had ever tried e-cigarettes, 9.7\% $(\mathrm{N}=3)$ of younger non-smokers, $46.3 \% \quad(\mathrm{~N}=63)$ of younger smokers and $43.1 \%(\mathrm{~N}=53)$ of older smokers reported trying an e-cigarette that contained nicotine. Additionally, 33.3\% $(\mathrm{N}=1)$ of younger non-smokers, $85.7 \% \quad(\mathrm{~N}=54)$ of younger smokers and $88.7 \%$ of older smokers who had ever tried e-cigarettes reported that the last e-cigarette they used contained nicotine. A logistic regression model adjusted for sex, ethnicity and education revealed that reports of using an e-cigarette with nicotine varied by smoking status $\left(\chi^{2}=11.66, \mathrm{p}=0.003\right)$. Younger non-smokers were less likely to try e-cigarettes containing nicotine compared to younger smokers $(\mathrm{OR}=0.11,95 \%$ CI 0.03 to $0.40 ; \mathrm{p}=0.001)$ and older smokers $(\mathrm{OR}=0.15,95 \%$ CI 0.04 to $0.51 ; \mathrm{p}=0.003)$. There was no significant difference between younger smokers and older smokers trying e-cigarettes containing nicotine ( $\mathrm{OR}=0.79,95 \%$ CI 0.47 to $1.31 ; \mathrm{p}=0.36)$.

Among respondents who had ever tried e-cigarettes, $3.2 \%(\mathrm{~N}=10)$ of younger non-smokers, $13.6 \% \quad(\mathrm{~N}=44)$ of younger smokers and $7.2 \%(\mathrm{~N}=33)$ of older smokers did not know the brand of e-cigarettes they used. The most common brands reported by those who had ever tried e-cigarettes was VaPUR, Blu and other. Among respondents who currently use e-cigarettes $(\mathrm{N}=105)$, zero younger non-smokers, $47.4 \%(\mathrm{~N}=27)$ of younger smokers and $52.2 \%$ $(\mathrm{N}=24)$ of older smokers reported having a usual e-cigarette brand, with similar brand frequencies as ever users.

\section{Reasons for e-cigarette use}

Table 4 shows participants' reasons for trying e-cigarettes. The most common reason for trying e-cigarettes was curiosity among ever e-cigarette users who were younger non-smokers and older smokers. Furthermore, among current e-cigarette users, the most common reasons for current use were to help quit smoking, less harmful than smoking and taste. In

Table 4 Reasons for e-cigarette ever use $(\mathrm{N}=304)$

\begin{tabular}{|c|c|c|c|}
\hline & $\begin{array}{l}\text { Younger non-smokers } \\
16-24 \text { years } \\
(\mathrm{N}=31) \\
\%(n)\end{array}$ & $\begin{array}{l}\text { Younger smokers } \\
16-24 \text { years } \\
(N=136) \\
\%(n)\end{array}$ & $\begin{array}{l}\text { Older smokers } \\
25+\text { years } \\
(\mathrm{N}=123) \\
\%(\mathrm{n})\end{array}$ \\
\hline Curious & $54.8(17)$ & $40.4(55)$ & $34.1(42)$ \\
\hline Offered one & 38.7 (12) & $40.4(55)$ & $30.1(37)$ \\
\hline Taste & $32.3(10)$ & $18.4(25)$ & $6.5(8)$ \\
\hline Fun & $25.8(8)$ & $14.7(20)$ & $7.3(9)$ \\
\hline Less harmful than cigarettes & $16.1(5)$ & $14.0(19)$ & $32.5(40)$ \\
\hline Help quit smoking & - & $27.2(37)$ & $56.9(70)$ \\
\hline Use in places where I could not smoke & - & $12.5(17)$ & $19.5(24)$ \\
\hline Other & $9.7(3)$ & $2.2(3)$ & $4.1(5)$ \\
\hline Do not know & $3.2(1)$ & $1.5(2)$ & $0.8(1)$ \\
\hline
\end{tabular}


addition, $44 \%$ of smokers would consider using the nicotine patch, gum or lozenge; $43.6 \%$ would consider using an e-cigarette, and $21 \%$ would consider using prescription medication to help quit smoking.

\section{DISCUSSION}

Despite a ban on nicotine-containing e-cigarettes in Canada, the current findings indicate that the trial of e-cigarettes has increased among smokers and nonsmokers. The majority of participants were aware of e-cigarettes, which is consistent with levels of awareness observed in a recent US study, but much higher than previous Canadian estimates. ${ }^{8} 9$ The findings also indicate an increase in the trial of e-cigarettes by Canadians. The proportion of non-smokers trying e-cigarettes nearly doubled from a 2012 Canadian survey using the same methodology. ${ }^{12}$ However, the current findings indicate that current use of e-cigarettes among non-smokers is very rare; indeed, only 1 of 311 younger non-smokers surveyed reported using an e-cigarette in the past month.

Among smokers, rates of ever and current use of e-cigarettes were similar to 2012 Canadian estimates. ${ }^{12}$ Compared to other countries, the current data suggest that e-cigarette use in Canada is less prevalent than the UK, and closer to US estimates; ${ }^{8} 1619$ however, comparisons across countries are complicated by diversity in the samples and survey methodology. Even among smokers who reported use in the past month, less than one in five reported using e-cigarettes daily. This low rate of daily use suggests that relatively few e-cigarette users are using e-cigarettes as a regular 'substitute' for conventional cigarettes. This may be a reflection of the Canadian market in which nicotine containing e-cigarettes are banned; however, low levels of daily use have been noted in other markets, such as the US. ${ }^{20}$

Consistent with previous studies, younger smokers were more likely to use e-cigarettes than older smokers. ${ }^{9}$ Males were also more likely to use e-cigarettes compared to females, although no differences were observed across education levels, in contrast to previous data suggesting higher rates of use among more educated groups. ${ }^{20}$ Dual use of tobacco cigarettes and e-cigarettes was reported in the current study. Approximately $13 \%$ of smokers currently used e-cigarettes, which is similar to previous estimates that reported between $12 \%$ and $34 \%$ of dual use. ${ }^{11}$ A majority of participants reported using a tobacco cigarette first; however, there was evidence of participants trying an e-cigarette before ever using a tobacco cigarette. It is important to note that the current data regarding individuals who tried an e-cigarette before a tobacco cigarette does not necessarily constitute evidence of a 'gateway' effect. As discussed elsewhere, this temporal order could be due to common causes with respect to risk-taking predisposition or environmental and social influences, including easier access to e-cigarettes. ${ }^{21}$
Smokers reported a variety of reasons for using e-cigarettes. The most common reason among current users was to quit smoking. In fact, smokers reported greater intention to use e-cigarettes than prescription medication to quit smoking, with similar levels of intention to use e-cigarettes as for NRT. These findings provide additional evidence that e-cigarettes are being used as a quit aid. ${ }^{16}$ In addition, smokers reported using e-cigarettes for other reasons, such as for use in places where smoking is not allowed. Additional research is needed to examine whether using e-cigarettes for these reasons acts to sustain smoking over time or whether periods of temporary abstinence from cigarettes may promote future quit attempts. ${ }^{22}$ These results highlight the importance of assessing reasons for use when using population-based surveys to estimate the cessation rate of e-cigarette use. Analyses should not assume that all e-cigarette use is for the purpose of quitting and it may be inappropriate to include all users in the denominator when calculating quit rates.

The current findings also shed light on the use of e-cigarettes with respect to two important product characteristics: flavour and nicotine. In the current study, the most common e-cigarette flavours used were fruit, menthol, tobacco and candy, similar to previous studies indicating that e-cigarette users prefer sweet and tobacco flavoured e-cigarettes. ${ }^{15}$ Furthermore, a study reported that among e-cigarette users, tobacco flavours were more popular at the beginning of using e-cigarettes, whereas fruit flavours were popular afterwards. ${ }^{23}$ The present study also indicated that younger smokers were more likely to try flavoured e-cigarettes than older smokers, but somewhat surprisingly, younger non-smokers were less likely to report trying flavoured e-cigarettes compared to smokers.

Although e-cigarettes with nicotine are prohibited in Canada, many participants in this study reported trying an e-cigarette with nicotine. Smokers were significantly more likely to report using e-cigarettes with nicotine than younger non-smokers. Interestingly, some of the participants who tried e-cigarettes did not know what brand they used, which may be explained by the use of refillable 'tank' systems. Branding of the refillable liquids ('e-juice') is much less prominent-and sometimes largely absent—compared to disposable e-cigarettes.

\section{Strengths and limitations}

This study has several limitations common to crosssectional survey designs, including an inability to establish temporal order. For example, although the study could assess reasons for use, such as for quitting smoking, the study could not assess the efficacy of e-cigarettes as a cessation device. In addition, participants were not recruited through random sampling. Therefore, although the sample is large with a diverse profile, it is not representative of the Canadian population. Indeed, the current study sample had an unusually high prevalence of smoking. To account for this 
limitation, regression models were adjusted for smoking status, sex, ethnicity and education. The inclusion of both smokers and non-smokers in the sample as well as measures of ever and current use of e-cigarettes are strengths given the ability to compare patterns of use.

\section{Implications}

The current study indicates that e-cigarette trial is increasing in Canada despite prohibitions on the sale of e-cigarettes with nicotine. The findings suggest that Canadians may be using a mix of 'legal' non-nicotine e-cigarettes and 'illegal' nicotine-containing e-cigarettes, a finding that warrants closer investigation. Patterns of use of e-cigarettes in Canada appear to be similar to those in jurisdictions without sales bans, including increasing rates of experimentation among non-smokers, but very low levels of continued use among this subpopulation.

Acknowledgements The authors would like to thank Christine White for her assistance with the survey administration.

Contributors SS analysed and interpreted the data, wrote the paper, submitted the paper, and agreed to be accountable for all aspects of the work. CDC planned the study, helped design the survey, revised the content of the work, approved the final copy to be published, and agreed to be accountable for all aspects of the work. DH contributed substantially to the design of the study, and the analysis and interpretation of the data, revised the content of the work, approved the final copy to be published, and agreed to be accountable for the overall work as guarantor.

Funding This work was supported by a Canadian Institute of Health Research (CIHR) Training Grant in Population Intervention for Chronic Disease Prevention: A Pan-Canadian Program (grant \#53893), a CIHR Vanier Canada Graduate Scholarship, a CIHR New Investigator Award and a Canadian Cancer Society Research Institute Junior Investigator Research Award.

\section{Competing interests None declared.}

Ethics approval The study received approval from the Office of Research Ethics at the University of Waterloo.

Provenance and peer review Not commissioned; externally peer reviewed.

Data sharing statement Requests for additional unpublished data from the study are available by emailing dhammond@uwaterloo.ca.

Open Access This is an Open Access article distributed in accordance with the Creative Commons Attribution Non Commercial (CC BY-NC 4.0) license, which permits others to distribute, remix, adapt, build upon this work noncommercially, and license their derivative works on different terms, provided the original work is properly cited and the use is non-commercial. See: http:// creativecommons.org/licenses/by-nc/4.0/

\section{REFERENCES}

1. Krueger H, Turner D, Krueger J, et al. The economic benefits of risk factor reduction in Canada: tobacco smoking, excess weight and physical inactivity. Can J Public Health 2014; 105: e69-78.
2. International Agency for Research on Cancer [IARC]. Tobacco smoke and involuntary smoking. IARC monographs on the evaluation of carcinogenic risks to humans. Vol 83. Lyon, France: IARC Press, 2004.

3. Benowitz NL, Goniewicz ML. The regulatory challenge of electronic cigarettes. JAMA 2013;310:685-6.

4. Farsalinos KE, Polosa R. Safety evaluation and risk assessment of electronic cigarettes as tobacco cigarette substitutes: a systematic review. Ther Adv Drug Saf 2014;2:67-86.

5. Hajek P, Etter JF, Benowitz N, et al. Electronic cigarettes: review of use, content, safety, effects on smokers and potential for harm and benefit. Addiction 2014;109:1801-10 (accessed 21 Aug 2014).

6. The Globe and Mail. The high-stakes debate over e-cigarettes. http:// www.theglobeandmail.com/life/health-and-fitness/health/the-highstakes-debate-over-e-cigarettes/article16628859/ (accessed 2 Feb 2014).

7. Besaratinia A, Tommasi S. Electronic cigarettes: the road ahead. Prev Med 2014;66:65-7.

8. Zhu S, Gamst A, Lee M, et al. The use and perception of electronic cigarettes and Snus among the U.S. population. PLOS ONE 2013;8: e79332.

9. Adkison SE, O'Connor RJ, Bansal-Travers M, et al. Electronic nicotine delivery systems international tobacco control four-country survey. Am J Prev Med 2013;44:207-15.

10. King BA, Alam S, Promoff G, et al. Awareness and ever-use of electronic cigarettes among U.S. adults, 2010-2011. Nicotine Tob Res 2013;15:1623-7.

11. Pepper JK, Brewer NT. Electronic nicotine delivery system (electronic cigarette) awareness, use, reactions and beliefs: a systematic review. Tob Control 2014;23:375-84.

12. Czoli CD, Hammond D, White CM. Electronic cigarettes in Canada: prevalence of use and perceptions among youth and young adults. Can J Public Health 2014;105:e97-102.

13. Goniewicz ML, Kuma T, Gawron M, et al. Nicotine levels in electronic cigarettes. Nicotine Tob Res 2013;15:158-66.

14. Etter J. Electronic cigarettes: a survey of users. BMC Public Health 2010;10:231.

15. Dawkins L, Turner J, Roberts A, et al. 'Vaping' profiles and preferences: an online survey of electronic cigarette users. Addiction 2013;108:1115-25

16. West R, Brown J. The Smoking Toolkit Study: a brief summary. 2012. http://www.smokinginengland.info/latest-statistics/ (accessed 21 Aug 2014).

17. Health Canada. Notice-To All Persons Interested in Importing, Advertising or Selling Electronic Smoking Products in Canada. http:// www.hc-sc.gc.ca/dhp-mps/prodpharma/applic-demande/pol/notice_ avis_e-cig-eng.php (accessed Apr 2014).

18. Health Canada. Health Canada Advises Canadians Not to Use Electronic Cigarettes. http://www.healthycanadians.gc.ca/recall-alertrappel-avis/hc-sc/2009/13373a-eng.php (accessed Apr 2014).

19. Brown J, West $\mathrm{R}$, Beard $\mathrm{E}$, et al. Prevalence and characteristics of e-cigarette users in Great Britain: findings from a general population survey of smokers. Addict Behav 2014;39:1120-5.

20. Citigroup Global Markets Inc. E-cigarettes: early adopters an per capita conundrum. Citi Research Equities Report. October 2013.

21. Degenhardt L, Dierker L, Chiu WT, et al. Evaluating the drug use "gateway" theory using cross-national data: consistency and associations of the order of initiation of drug use among participants in the WHO World Mental Health Surveys. Drug Alcohol Depend 2010;108:84-97.

22. Beard E, McNeill A, Aveyard P, et al. Association between use of nicotine replacement therapy for harm reduction and smoking cessation: a prospective study of English smokers. Tob Control 2013;22:118-22.

23. Farsalinos KE, Romagna G, Tsiapras D, et al. Impact of flavour variability on electronic cigarette use experience: an internet survey. Int J Environ Res Public Health 2013;10:7272-82. 